\title{
Study of the Midwifery Care in 6 Obstetrical Facilities in Okinawa-Self- Completed Retrospective Questionnaires for One Month Postpartum Women
}

\author{
Yoko Tamashiro $^{1}$, Fujiko Omine ${ }^{1}$, Yumiko Endoh ${ }^{1}$, Tsugiko Gima ${ }^{1}$, Chikako Maeshiro ${ }^{1}$, Noriko Toyama ${ }^{2}$, Rika Takemoto $^{2}$, \\ Tomomi Takayama ${ }^{2}$ and Miki Hirata ${ }^{2}$ \\ ${ }^{1}$ Department of Health Sciences, University of the Ryukyus, 1 Senbaru, Nishihara-cho, Nakagami-gun, Okinawa, Japan \\ ${ }^{2}$ Graduate School of Health Sciences, University of the Ryukyus, 1 Senbaru, Nishihara-cho, Nakagami-gun, Okinawa, Japan
}

\begin{abstract}
The purpose of this study was to investigate the effective midwifery care from pregnancy to postpartum in order to promote evidence-based midwifery practice in improving childbirth satisfaction and breastfeeding. The subjects were one-month postpartum mothers who came to one-month check-up during July to October in 2010. The purpose of the self-administered questionnaire developed by the research group was explained, then provided to mothers who agreed to participate in the survey at 4 hospitals each with more than 300 beds and 1 clinic with more than 500 deliveries annually in Okinawa. The questionnaire was collected on the same day or via postal mail. A total of 540 mothers agreed to complete the survey, and 434 responses were considered valid for this study (valid response rate: 80.4\%). Vaginal delivery group was 223 (82.3\% with medical intervention rate of $15.2 \%)$, and the cesarean section group was 48 (17.7\%). The most helpful one-on-one guidance was "nipple care in preparation for breastfeeding" during pregnancy, "encouragement" during delivery, and "Kangaroo (skin-to-skin) care" immediately after the delivery. An Application rate of episiotomy was $65.2 \%$ for primiparous women and $30.5 \%$ for multiparous women. The rate of perineal laceration enlarged to more than third degree in cases with episiotomy is three times more than the cases with no episiotomy. Additionally, the prevalence of breastfeeding at one-month postpartum was significantly higher in the mothers rooming-in with the baby $(76.2 \%)$ than mothers in separate room $(28.3 \%)$. Moreover, $60.3 \%$ of the mothers in the complete rooming-in group answered they had not felt difficulty with childcare while it dropped to $46.2 \%$ among the mothers in the separate room group.
\end{abstract}

\begin{abstract}
Background
Contrary to the high birth rate, Okinawa is faced with mother-child health issues such as highest rate of low birth weight babies, youth pregnancies/deliveries, not receiving pregnancy check-ups, highest divorce rate and child poverty rate among other prefectures in Japan [1]. The need for continuous complete support system is called for from doctors and midwives for women starting in the gestation period. At the private practices and birth centers which are the primary places for delivery in the communities, midwives have placed importance on midwifery care which enhances self-care skills during the gestation period through one-on-one birth preparation education.

childcare and more willingness for next pregnancy [7]. Today, on top of isolation during childcare periods, women' views towards marriage and career have changed. The number of mothers with postpartum depression and maternity neurosis have increased, and the need to support mothers under difficult situation that could lead to infant and child abuse is increasing more than ever [8]. Child care starts with pregnancy. This is why we need to show the effectiveness of midwife care as childcare support, which enables women to prepare for the coming delivery with physical and emotional confidence, overcome child birth more safely and comfortably, decrease the feeling of postpartum childcare burden, and transit smoothly into breastfeeding stage.
\end{abstract}

The prenatal check-ups have an important role in managing the health of the pregnant women and newborn babies. However, it has become apparent that the degree of understanding of the importance varies among pregnant women receiving the prenatal health guidance, and that most of the women reach delivery without going through or implementing the content of the supplementary readers or materials provided during parents' classes or when they are issued the motherchild notebook [2]. On the contrary, pregnant women who received an ample education on birth preparation have indicated to have less fear towards birth and lead to a good delivery experience [3]. It is also reported that the good delivery experience decreases childcare stress, and prevent postpartum depression [4]. Postpartum depression can be connected to difficulty with childcare, attachment disorder, and infant abuse during childcare period, and has become a serious social issue in Japan [5]. Also, there are researches that show low-risk pregnant women with low level of birth satisfaction have a high tendency of depression and high level of response to stress [6]. These studies also indicate that high level of birth satisfaction lead to satisfaction of

\section{Materials and Methods}

The subjects were one-month postpartum mothers who came to check-ups from July to October in 2010 . We conducted the study at 4 hospitals and 1 clinic in Okinawa, Japan. A total of 540 mothers agreed to complete the survey, and 434 responses were considered

"Corresponding Author: Dr. Yumiko Endoh, Department of Health Sciences, University of the Ryukyus, 207 Uehara, Nishihara-cho, Nakagami-gun, Okinawa, Japan, Tel: 098-895-1269; E-mail: eyumi@med.u-ryukyu.ac.jp

Citation: Tamashiro Y, Omine F, Endoh Y, Gima T, Maeshiro C, et al. (2017) Study of the Midwifery Care in 6 Obstetrical Facilities in Okinawa-Self-Completed Retrospective Questionnaires for One Month Postpartum Women. Int J Nurs Clin Pract 4: 254. doi: https://doi.org/10.15344/2394-4978/2017/254

Copyright: (C) 2017 Tamashiro et al. This is an open-access article distributed under the terms of the Creative Commons Attribution License, which permits unrestricted use, distribution, and reproduction in any medium, provided the original author and source are credited. 
Citation: Tamashiro Y, Omine F, Endoh Y, Gima T, Maeshiro C, et al. (2017) Study of the Midwifery Care in 6 Obstetrical Facilities in Okinawa-Self-Completed Retrospective Questionnaires for One Month Postpartum Women. Int J Nurs Clin Pract 4: 254. doi: https://doi.org/10.15344/2394-4978/2017/254

Page 2 of 6

valid for this study. After explaining the purpose of the survey, a selfadministered questionnaire developed by this research group was provided to the agreed mothers. The questionnaire was collected on the same day or via postal mail at a later date. The subjects' attribute surveyed were: age, occupation, family type, obstetric factors such as gestational age in weeks, delivery method, baby's birth weight, Apgar score at birth, hemorrhage volume at delivery and application of episiotomy as controlled variables. The questionnaire asked about midwife care received during pregnancy, delivery, and postpartum, application of medical procedures such as episiotomy during vaginal delivery, degree of pain after delivery, types of midwife care during hospital stay and their effects, rooming-in with baby, breastfeeding, feeling of burden in childcare indication [8] items, Likert's 5 point scale method, a coefficient) by Nakajima et al. [9]. The cutoff number was 9.7 for the total sum of 8 items in feeling of burden in childcare indication, and more than 9.7 in feeling the child care burden. The details of delivery were obtained from medical records (midwife $\log$ ) with permission from the subjects. For the analysis method, we developed descriptive statistics against subjects' demographic information, and used the Chi-square test as well as Mann Whitney $\mathrm{U}$ test (SPSS Ver.18) to compare the relative factors influencing midwifery care (such as per primiparous/multiparous women). Statistical significance was set at less than $5 \%$ each.

For ethical considerations to conduct the research, the following were explained in writing: the purpose of the study, the questionnaire was anonymous, a subject was to answer questions on a voluntary basis and could choose not to participate at any time, nonparticipation would not cause them any disadvantages, data will be processed statistically, saved securely, and not be used for anything other than the study, and will be destroyed after published as an article or presented at academic conferences within 5 years. Consent was assumed by filled-out questionnaire. Referencing midwife log was done upon receiving consent from the women and facility managers. This study was approved by the University of the Ryukyus ethical committee.

\section{Results}

The mean age is $30.9 \pm 4.8$ years. There were no differences found in employment rate, family members, gestational age in weeks, delivery method, baby's birth weight, Apgar score at birth, hemorrhage volume at delivery and primi- or multiparous. The numbers were in the standard range. The episiotomy rate showed a difference between primi- and multiparous women with $48.4 \%$ for primiparous women and $23.0 \%$ for multiparous women. When subjects were categorized by delivery method, we found 140 vaginal deliveries (77.0\%) and 34 cesarean sections (19.0\%) for primiparous women, and 166 vaginal deliveries $(66.0 \%)$ and 43 cesarean sections $(17.0 \%)$ for multiparous women. Furthermore, vaginal deliveries were categorized by natural deliveries with no medical intervention and those that were artificially induced or vacuumed. For primiparous/vaginal delivery group, the rate of receiving medical intervention was $10 \%$, whereas for multiparous/vaginal delivery group, there was a slight increase of $17.0 \%$. An application rate of episiotomy was $65.2 \%$ for primiparous women and $30.5 \%$ for multiparous women (Table 1 ).

Top 3 most useful midwife care chosen during pregnancy, intrapartum, and postpartum periods were "nipple care" to prepare for breastfeeding, "exercises and stretch," and "weight control" for pregnancy period. As for intra-partum stage, "encouragements" scored the highest, followed by "always staying by my side" as effective care in reducing discomfort and pain during delivery. The highest in postpartum stage was "early skin-to-skin contact/breastfeeding (kangaroo care)" followed by "rooming-in with the baby" and "pain killers" (Table 2).

Since the degree of tear is second degree when episiotomy is applied, we compared groups with second degree or more tear who had episiotomy and who did not. (In second degree tear, laceration extends to perineum muscular layer, but not anal sphincter. In third degree tear, anal sphincter is torn but not rectal mucosa. In fourth degree

\begin{tabular}{|c|c|c|c|c|}
\hline & & Primipara $n=182$ & Multipara $n=252$ & $\mathrm{p}$-value \\
\hline Age & Mean \pm SD & $29.7 \pm 5.1$ & $32.0 \pm 4.7$ & n.s. \\
\hline Occupation & $\begin{array}{l}\text { Homemaker } \\
\text { Working woman } \\
\text { Unknown }\end{array}$ & $\begin{array}{l}49.5(90) \\
48.4(88) \\
2.2(4)\end{array}$ & $\begin{array}{l}48.4(122) \\
50.0(126) \\
1.6(4)\end{array}$ & n.s. \\
\hline Family form & $\begin{array}{l}\text { Nuclear family } \\
\text { Step family } \\
\text { Unknown }\end{array}$ & $\begin{array}{c}74.7(136) \\
20.9(38) \\
4.4(8)\end{array}$ & $\begin{array}{l}71.0(179) \\
26.2(66) \\
2.8(7)\end{array}$ & n.s. \\
\hline Gestational age weeks & Mean \pm SD & $39.3 \pm 1.6$ & $39.2 \pm 1.3$ & n.s. \\
\hline Delivery form & $\begin{array}{l}\text { Normal vaginal } \\
\text { Artificial labor (Induced. or Vacuum. ) } \\
\text { Cesarean section }\end{array}$ & $\begin{array}{l}77.0(140) \\
10.0(18) \\
19.0(34)\end{array}$ & $\begin{array}{l}66.0(166) \\
17.0(43) \\
17.0(43)\end{array}$ & n.s. \\
\hline Birth weight & Mean \pm SD & $2948.2 \pm 407.8$ & $3063.8 \pm 432.7$ & n.s. \\
\hline Apgar score $\quad$ Mean \pm SD & $\begin{array}{l}1 \text { minute values } \\
5 \text { minutes values }\end{array}$ & $\begin{array}{l}8.3 \pm 0.8 \\
8.9 \pm 0.6\end{array}$ & $\begin{array}{l}8.4 \pm 0.8 \\
9.1 \pm 0.5\end{array}$ & n.s. \\
\hline Birth weight & Mean \pm SD & $464.9 \pm 303.4$ & $478.1 \pm 341.2$ & \\
\hline Adoption of episiotomy $\%(n)$ & $\begin{array}{l}\text { Yes } \\
\text { No } \\
\text { Unknown }\end{array}$ & $\begin{array}{l}48.4(88) \\
30.2(55) \\
21.4(39)\end{array}$ & $\begin{array}{c}21.8(55) \\
56.1(140) \\
22.6(57)\end{array}$ & $<.05$ \\
\hline
\end{tabular}

Table 1: The correlation between backgrounds of postpartum women.

Chi square test or Mann Whitney U test 
Citation: Tamashiro Y, Omine F, Endoh Y, Gima T, Maeshiro C, et al. (2017) Study of the Midwifery Care in 6 Obstetrical Facilities in Okinawa-Self-Completed Retrospective Questionnaires for One Month Postpartum Women. Int J Nurs Clin Pract 4: 254. doi: https://doi.org/10.15344/2394-4978/2017/254

Page 3 of 6

\begin{tabular}{|c|c|c|c|}
\hline Ranking & 1 & 2 & 3 \\
\hline Perinatal stage & Breast feeding & Ex) \\
\hline $\begin{array}{c}\text { Pregnant } \\
(95)\end{array}$ & $49.5(47)$ & $29.5(28)$ & $\begin{array}{c}\text { Weight restrictions } \\
21.0(20)\end{array}$ \\
\hline Intrapartum & Continuing encouragement & Stay by the side consistently & Instruction of breathing \\
(85) & $52.9(45)$ & 25.9 (22) & Rooming-in killers \\
\hline Postpartum & Early skin to skin contact \& \\
(98) & breastfeeding & $21.4(21)$ & $20.4(20)$ \\
\hline
\end{tabular}

The the three helpful midwifery care chosen by the post-partum women.

\begin{tabular}{|c|c|c|c|c|c|}
\hline & & \multicolumn{2}{|c|}{ The degree of laceration } & \multicolumn{2}{|r|}{$\%(\mathrm{n})$} \\
\hline & & $\begin{array}{c}\text { Without } \\
\text { Laceration } \\
(53)\end{array}$ & $\begin{array}{c}1^{\text {st }} \text { degree } \\
(20)\end{array}$ & $\begin{array}{c}2^{\text {nd }} \text { degree } \\
(238)\end{array}$ & $\begin{array}{c}\text { More than } 3^{\text {rd }} \\
\text { degree } \\
(27)\end{array}$ \\
\hline $\begin{array}{l}\text { Without } \\
\text { episiotomy } \\
\text { (195) }\end{array}$ & $\begin{array}{c}\text { Primiparous } \\
\qquad(58) \\
\text { Multiparous } \\
(137)\end{array}$ & $\begin{array}{l}12.1(7) \\
33.1(46)\end{array}$ & $\begin{array}{c}6.9(4) \\
11.5(16)\end{array}$ & $\begin{array}{l}72.4(42) \\
54.0(75)\end{array}$ & $\begin{array}{l}8.6(5) \\
0(0)\end{array}$ \\
\hline $\begin{array}{c}\text { With } \\
\text { episiotomy } \\
(143)\end{array}$ & $\begin{array}{c}\text { Primiparous } \\
\text { (88) } \\
\text { Multiparous } \\
\text { (55) }\end{array}$ & & & $\begin{array}{l}80.7(71) \\
90.9(50)\end{array}$ & $\begin{array}{l}19.3(17) \\
9.1(5)\end{array}$ \\
\hline
\end{tabular}

Table 3(a): With or without Episiotomy and Degree of Laceration

\begin{tabular}{|c|c|c|c|}
\hline \multirow{2}{*}{} & \multicolumn{2}{|c|}{ The degree of laceration $\%(\mathrm{n})$} & \multirow{2}{*}{ p-value } \\
\cline { 2 - 3 } & $2^{\text {nd }}$ degree (238) & More than $3^{\text {rd }}$ degree $(27)$ & \\
\hline $\begin{array}{c}\text { Without episiotomy } \\
(122)\end{array}$ & $95.9(117)$ & $4.1(5)$ & \\
\hline $\begin{array}{c}\text { With episiotomy } \\
(143)\end{array}$ & $84.6(121)$ & $15.4(22)$ & $<.05$ \\
\hline
\end{tabular}

Table 3(b): The correlation between with or without episiotomy and more than 2 nd degree laceration.

Chi square test

\begin{tabular}{|c|c|c|c|c|c|}
\hline Perineal pain & $\begin{array}{c}\text { Severe pain } \\
(128)\end{array}$ & $\begin{array}{l}\text { Mediocre pain } \\
(58)\end{array}$ & $\begin{array}{c}\text { Mild/Not-bad pain } \\
\text { (66) }\end{array}$ & $\begin{array}{l}\text { Unknown } \\
\text { (13) }\end{array}$ & p-value \\
\hline $\begin{array}{l}\text { Without episiotomy } \\
\text { 2nd degree laceration \& more than 3rd } \\
\text { degree (122) }\end{array}$ & $45.1(55)$ & $28.7(35)$ & $24.6(30)$ & $1.6(2)$ & \multirow[t]{2}{*}{ n.s. } \\
\hline $\begin{array}{l}\text { With episiotomy } \\
\text { 2nd degree laceration \& extended to } \\
\text { more than 3rd degree } \\
(143)\end{array}$ & $51.1(73)$ & $16.1(23)$ & $25.2(36)$ & $7.7(11)$ & \\
\hline
\end{tabular}

tear, laceration extends to rectal mucosa. Third and fourth degree tears are called high degree perineal tear for a high degree of damage.) In group with episiotomy, there were three times more women who had extended tear of third degree or more than the group without episiotomy in both primiparous and multiparous women (Table 3a and Table 3b). Post-episiotomy and laceration pain were asked to be rated in three-point scale as "severe pain," "mediocre pain," and "mild pain/not bad pain," and the results showed no difference in the degree of pain between episiotomy and laceration (Table 4).

For exclusive breastfeeding and rooming-in with the baby at one month after the delivery, the group of full rooming-in had the highest breastfeeding rate which pushed the overall breastfeeding rate.
Women with more than the cut off rate of average total 9.7 on the child care burden scale was categorized in the group as having childcare burden, and women with less than 9.7 was of not having childcare burden. Furthermore, in investigating the correlation between childcare burden and full rooming-in during one month after delivery, $60.3 \%$ of the rooming-in group rated having no feeling of childcare burden, where the nursery care (non-roomingin) group rated $46.2 \%$. Having the feeling of childcare burden was rated $29.4 \%$ among the rooming-in group, whereas the nursery care (non-rooming-in) group rated $38.6 \%$. The full rooming-in group showed having no feeling of childcare burden. On the contrary, there was a tendency for non-full rooming-in group to have the feeling of childcare burden (Table 5). 
Citation: Tamashiro Y, Omine F, Endoh Y, Gima T, Maeshiro C, et al. (2017) Study of the Midwifery Care in 6 Obstetrical Facilities in Okinawa-Self-Completed Retrospective Questionnaires for One Month Postpartum Women. Int J Nurs Clin Pract 4: 254. doi: https://doi.org/10.15344/2394-4978/2017/254

Page 4 of 6

\section{Discussion}

We investigated what were effective as medical, midwifery, and nursing care during intra-partum period, for women during pregnancy through post-partum period from the view of one month postpartum mothers. As a result, there was no difference between primiparous and multiparous women, and both groups showed numbers within the normal range when comparing the subjects' attributes and background such as delivery situation. The application of episiotomy was one area that indicated a difference between primiparous and multiparous women; with the former $48.4 \%$ and the latter $23.0 \%$. However, since the application rate for primiparous women was low compared to the national average of 60 to $70 \%$ [10], it shows that application standard of episiotomy has been limited to such cases where shortening of delivery time was necessary due to worsening of fetus' health status. Furthermore, categorizing subjects by delivery method gives us 140 vaginal deliveries (77.0\%) and 34 cesarean sections (19.0\%) in primiparous women, and $166(66.0 \%)$ and $43(17.0 \%)$ respectfully in multiparous women, which indicates our subjects were low risk pregnant women with low rate of cesarean section. In comparison between natural birth group without medical intervention and group with medical intervention such as induced or vacuumed delivery in vaginal deliveries, medical intervention rate was $10.0 \%$ for primiparous women and $17.0 \%$ for multiparous women which showed a tendency of slight increase. This result can be attributed to a recent rise in women's childbearing age.

The care rated as most useful during pregnancy was "nipple care" in preparation for breastfeeding followed by "exercise and stretching" and "weight control." According to 2015 infants diet study (Japan Ministry of Health, Labour and Welfare), 93\% of women wish to raise a child solely on breast milk. We believe the result of our study show that these increasing expectation of care for breastfeeding preparation were met.

Also, the high rating for exercise and weight control shows the needs for natural birth since exercise and weight control play an important role as self-care for pregnant women having a natural birth.
"Encouragement" followed by "being by my side all the time" was the highest rated care received during delivery that were effective in easing pain and discomfort. Although it was unexpected that mental/ emotional care was rated as the highest care desired during delivery rather than the care of physical pain, we recognized the importance of mental/emotional care to support the woman during the most painful stage of child birth. Furthermore, the midwife care rated as being effective in easing postpartum pain and discomfort were early mother and infant contact/early breastfeeding (Kangaroo care) followed by rooming-in with the infant and painkiller administration. As this has been reported in previous studies, there is no doubt that immediate skin to skin contact with the baby and setting up breastfeeding to take place within 30 minutes after birth brings the effects of spiritual elevation which helps mothers to forget the pain and discomfort instantly [12]. From pregnancy period, midwives carry on birth preparation side by side with the expected mothers, listening to their needs/wants, reviewing birth plan including delivery style, and providing health guidance to ease minor troubles such as edema as well as pain during childbirth. At the time of labour, midwives pay attention to any deviance and provide necessary palliative care in attempts to lead the mothers to smooth delivery. Midwives have a critical role in normal childbirth spending large amount of time with the expecting mothers. Following labor, midwives continue to offer detailed individual assistance in the process of physical recovery, child care with the main focus on breastfeeding, changing diapers, bathing the baby, post-partum guidance including family planning, and so forth. Postpartum in-patient period is special for both the expecting mothers and midwives since in majority of the cases, one-on-one close relationship is built, and childbirth experience is received positively by expecting mothers. As for application rate of episiotomy, our study results showed $48.2 \%$ for primiparous women and $21.8 \%$ for multiparous women, which are rather low in comparison to Japan's average of 30$100 \%$ for primiparous [10]. In the Unites States also, episiotomy is a common medical practice carried out in $50-90 \%$ of childbirth cases by primiparous [13]. The top three reasons episiotomy is practiced in childbirth are first to prevent worsening of perineal laceration, second to prevent difficult delivery by enlarging the opening, and third in times of forced delivery when fetus heartbeat is unstable. In the last 20

\begin{tabular}{|c|c|c|c|c|}
\hline & & & & $\%(n)$ \\
\hline \multicolumn{2}{|c|}{ During hospitalization } & Rooming-in & $\begin{array}{l}\text { Without } \\
\text { rooming-in }\end{array}$ & $\mathrm{p}$-value \\
\hline \multirow{3}{*}{$\begin{array}{l}\text { Nutrition method } \\
\qquad(414)\end{array}$} & $\begin{array}{c}\text { Exclusive } \\
\text { breastfeeding } \\
(238)\end{array}$ & $74.7(162)$ & $38.6(76)$ & \multirow{3}{*}{$<.01$} \\
\hline & $\begin{array}{l}\text { Mixed feeding \& bottle feeding } \\
\text { (171) }\end{array}$ & $24.4(53)$ & $59.9(118)$ & \\
\hline & $\begin{array}{l}\text { Unknown } \\
\text { (5) }\end{array}$ & $0.9(2)$ & $1.5(3)$ & \\
\hline \multirow{3}{*}{$\begin{array}{c}\text { Burden of childcare } \\
\text { - total average of } 8 \text { scale item - } \\
(274)\end{array}$} & $\begin{array}{c}\text { Not really feel } \\
\text { burden of childcare } \\
\text { mean }<9.7(143)\end{array}$ & $60.3(76)$ & $46.2(67)$ & \multirow{3}{*}{$<.05$} \\
\hline & $\begin{array}{c}\text { Really feel } \\
\text { burden of childcare } \\
\text { mean } \geq 9.7 \text { (95) }\end{array}$ & 29.4(37) & $38.6(58)$ & \\
\hline & $\begin{array}{l}\text { Unknown } \\
\text { (36) }\end{array}$ & $10.3(14)$ & $15.2(22)$ & \\
\hline
\end{tabular}


Citation: Tamashiro Y, Omine F, Endoh Y, Gima T, Maeshiro C, et al. (2017) Study of the Midwifery Care in 6 Obstetrical Facilities in Okinawa-Self-Completed Retrospective Questionnaires for One Month Postpartum Women. Int J Nurs Clin Pract 4: 254. doi: https://doi.org/10.15344/2394-4978/2017/254

years, US has issued a warning limiting the application of episiotomy upon receiving the reports that evidence supporting the benefits of episiotomy is not substantial. The application rate now is 15-20\% [14]. In addition, there were more cases resulting in laceration with degree III and IV in groups with episiotomy compared to cases resulted in tearing without episiotomy. Although there is a lack of data in Japan, overseas research show that the risk of reaching higher degrees of laceration is three times more in cases with episiotomy than those without episiotomy [15]. In our study, the rate of perineal laceration enlarged to more than third degree in cases with episiotomy is three times more than the cases with no episiotomy. Although we had limited data, our study presented the same result as the previous studies conducted in overseas. This result indicates that operational incision using a tool such as scissors lead to higher degree laceration compared to natural tearing as evidence. One study shares their result that expecting mothers fear incision to their vaginal area and choose a midwife center in hopes to avoid such procedure as much as possible [16]. Considering the wishes of women and study results, application of episiotomy should be limited to minimum by health professionals at obstetric facilities. Using the 3 point scale rating (severe pain, moderate pain, barely noticeable pain), we also studied women's subjective pain when they walk and excrete after episiotomy/ tearing. As a result, within the group of women with more than second degree incision/tearing, there was no difference in the degree of pain regardless of incision or tearing, however, half of the incision group (51.1\%) as well as the tearing group (45.1\%) claimed that they experienced "severe pain." Further investigation deems necessary with more cases grouped by degree of incision/tearing.

What became apparent from the relationship between full room-in with the infant during hospitalization, and exclusive breastfeeding as well as the feeling of childcare burden at one month after delivery, was that implementation of room-in with the baby significantly impacts the increase of exclusive breastfeeding rate and decrease of childcare burden at one month after delivery. Experience of spending day and night with infant during hospitalization (breastfeeding of infant as he cries) increases the secretion of oxytocin, gives positive effects to secretion of milk, and having skin to skin contact with infant further increases the secretion of oxytocin. We can say that this experience contributes to the high rate of exclusive breastfeeding at one month after delivery [17]. Furthermore, when we look at the correlation between women with more than the cut off rate of average total 9.7 on the childcare burden scale categorized as having childcare burden as well as women with less than 9.7 as not having childcare burden and full rooming-in during one month after delivery, $60.3 \%$ of the rooming-in group rated having no feeling of childcare burden, where the nursery care (non-rooming-in) group rated $46.2 \%$. Having the feeling of child care burden was rated $29.4 \%$ among the rooming-in group, whereas the nursery care (non-rooming-in) group rated $38.6 \%$. There was a tendency for women without the feeling of childcare burden in full rooming-in group to significantly increase while women with the feeling of childcare burden in non-full rooming-in group to increase. Hence, having the new born in the same room immediately after delivery and on helps decrease the feelings of childcare burden, and brings positive influence to breast milk secretion. These benefits outweigh the said disadvantage of rooming-in, which is fatigue brought to the postpartum women. Fukuda et al. reported that the effects of rooming-in range from naturally matching the timing of breastfeeding and sleeping hours to developing a lot of the mother's childcare skills in one week with individually customized care per her childbirth experiences or the lack of. The study also showed that rate of mothers indicating strong affection for the child increased whiles those who denied the child decreased [18]. The rooming-in in clinical setting starts a few days after hospitalization. This is to care for tired mother, help secure sleeping hours, but limits the direct breastfeeding opportunities by keeping the baby in nursing care at nights [19]. There are few facilities practicing rooming-in immediately after childbirth. Considering the effect early and frequent breastfeeding has on the period of establishing breast milk secretion, night time nursing care should be limited and instead promote midwives and nurses to assist with rooming-in and provide breastfeeding intervention.

\section{Conclusion}

We conducted the study in order to gain more information on promoting midwife care which lead to more satisfactory childbirth and effective childcare by breastfeeding. The data were collected by the means of survey on midwife care services and medical history inquiry to the mothers at one month post-partum in 5 childbirth facilities in Okinawa.

Shimada et al. has reported (2008) that women who received continuous one-on-one personal care and guidance during pregnancy have less medical interventions, and this continuous care is highly valued by them. It was concluded that the midwife care mothers evaluated as effective in easing the pain and discomfort during delivery were emotional care such as not leaving the mothers by themselves. After the child birth, early contact with infant and rooming-in service were found to be the best care. Also, the significant correlation between full mother-infant rooming-in group and exclusive breastfeeding rate confirmed the evidence that mother-infant rooming-in practice during hospitalization enables mothers to experience breastfeeding throughout the nights and to realize what daily life would be like with a newborn after discharge from the hospital. It also helps mothers to continue breastfeeding and reduce the burden of childcare. In order to increase the level of childbirth satisfaction, Sato et al suggests that we need to practice the following childbirth care as much as much possible: paying respect to and nurturing the pregnant mothers, explaining various medical procedures until they are fully understood, skin to skin contact immediately after delivery and breastfeeding, continuous care by the same staff throughout childbirth, and full mother-infant rooming-in [17]. The result of our study shows that skin to skin contact and breastfeeding immediately after delivery as well as mother-infant rooming-in heal the pain of childbirth, hence are evaluated highly. Midwives are expected to assist childbirth with skills to minimize tearing in natural childbirth and with attempts to avoid episiotomy as much as possible, which is the biggest concern for women during delivery. It has become clear that these skills and attempts contribute to the reduction in the number of women suffering from post-partum pain due to the high degree of laceration. Also, skin to skin contact with infant immediately after delivery and early mother-baby contact during room-in do not only ease the pain during labour, but also reduce the feeling of childcare burden at one month after childbirth and increase the exclusive breastfeeding rate significantly. This shows that mother-infant rooming-in is one of the major criteria for promoting childcare by breastfeeding. It's been concluded that providing complete rooming-in service for all, not only the mothers in private rooms, is essential in improving midwifery care.

Today, it is becoming more and more common to give birth at medical facilities, and due to shortage of doctors and midwives, it is also becoming even more difficult to attend to every need the 
Citation: Tamashiro Y, Omine F, Endoh Y, Gima T, Maeshiro C, et al. (2017) Study of the Midwifery Care in 6 Obstetrical Facilities in Okinawa-Self-Completed Retrospective Questionnaires for One Month Postpartum Women. Int J Nurs Clin Pract 4: 254. doi: https://doi.org/10.15344/2394-4978/2017/254

Page 6 of 6

mothers may have. On the other hand, childbirth scenes are changing gradually to meet mothers' expectations and bring satisfactions. Each facility is putting an effort to advance midwifery care, especially in midwives' areas of expertise, normal births. Experiencing labour that meets mothers' satisfaction and is filled with joy seems to give mothers the real feeling of motherhood and help produce invincible maternal affection. When women face labor not in a mechanical way but rather head on, and experience child birth that meets their expectations, we believe it leads to child rearing which brings enjoyment and fosters a desire for more children.

\section{Competing Interests}

The authors declare that they have no competing interests.

\section{Acknowledgements}

Our deep appreciation to mothers who participated in the study during their busy schedule with breastfeeding, childcare and so forth as well as the hospital and clinic staff who assisted us during their hectic work hours.

\section{References}

1. Health Promotion Division (2014) Department of Welfare and Health, Okinawa Prefecture: Healthy Parent and Child 21 Okinawa Report, Mother and Child Health Heisei 26: 8-10, 14-15.

2. Yamagata $Z$ (2014) Research on use and application of prenatal and infant check-up data for effective implementation of mother-child health programs: study report for Health Labour Sciences Research Grant: 1-28.

3. Megumi Haruna M (2015) Relationship between fear of labor and birth outcomes as well as stress hormones: study report for Japan Academy of Midwifery research grant: 1-82.

4. Sekiduka M (2005) Correlation between childbirth satisfaction and postpartum stress response. Journal of Japan Academy of Midwifery 19-2 19-27.

5. Takeda S (2016) Japan Society of Obstetrics and Gynecology etc: joint session on mental health of expectant and nursing mothers 2015 report: $1-11$.

6. Murakami A (2014) Economic insecurity and fertility intentions in Japan: University of Tokyo Institute of Social Science Panel Survey. Project Discussion Paper Series 80: 1-27.

7. Fukushima F, Hitsumoto S, Tounai S (2006) Study on the effect of Healthy Parent and Child 21 promotion 2nd Report: factors affecting satisfaction level in pregnancy, childbirth as well as child rearing, and motivation for childbirth. Japan Society of Public Health Meeting Abstract Collection 65: 676 .

8. Kitamura T, Minatani M, Ohashi Y (2015) Opinion on postnatal depression, child abuse, and infanticide.

9. Nakajima K, Saito Y, Okada S (199) Measurement tool for the feeling of parenting strain of mothers: guidance on welfare.

10. Kawai R (2001) Manual on choosing childbirth. Rural Culture Association 172-179.

11. Equal Employment, Child and Family Policy Bureau, Ministry of Health, Labour and Welfare, Japan (2015) Summary results of infant nutrition survey, Status on breastfeeding, Fiscal year Heisei 27: 3-15.

12. Ichikawa K, Kamada J (2009) How does a midwives' care effect mothers' valuable childbirth experience? Maternal Health 50: 79-87.

13. Woolley RJ (1980) Benefits and risks of episiotomy: a review of the Englishlanguage literature since Obstet Gynecol Surv 1995: 50:806-820, 821-835.

14. Friedman AM (2015) Variation in and factors associated with use of episiotomy. JAMA 313: 197-199.

15. Pel M, Heres MHB, Hart AAM, Van der Veen F, Treffers PE (1995) Providerassociated factors in obstetric interventions. Eur J Obstet Gynecol Reprod Biol 61: 129-134.

Int J Nurs Clin Pract

ISSN: $2394-4978$
16. Shimada M, Kamiya S, Nakane N, Murakami M (2008) National survey on continuous care from pregnancy to childbirth, satisfaction level, and clinical results. Journal of Japan Academy of Midwifery 21: 67.

17. Sato $Y$, Kato T, Ito R, Yan-Hong G, Kakee N (2007) Women's satisfaction and effective care at childbirth. Institute of child health 66-3: 465-471.

18. Fukuda M (1998) Study on future health management system for pregnant and postpartum women, The type of environment which fosters mother and child relationship and reduces postpartum child rearing anxiety after hospital discharge: 1997 Ministry of Health Labor and Welfare of Japan Mental and Physical Disability Research 75-78

19. Kondo K, Suzuki Y (2013) Advantages of rooming-in found by primiparas Analysis by KJ method (Report 1). Bulletin of Kiryu University 24: 95-102. 